\title{
RISCO E CONTINGÊNCIA
}

\section{Franz Josef Brüseke}

Um clima de crise teórica espalhou-se desde o final dos anos de 1970, cujas causas uns detectaram na "incredulidade nas metanarrativas" (Lyotard, 1979), outros na "crise do marxismo" (Althusser, 1978), outros simplesmente na "mudança paradigmática". Paralelamente foram constatados o "fim da história", o "fim da utopia" e o "fim do comunismo", a ponto de Robert Kurz exclamar: "nunca houve tanto fim!" (Fukuyama, 1992; Kurz, 1991). Estas afirmações, por vezes com uma existência passageira, por vezes em circulação até hoje, estão intimamente interligadas com eventos históricos das últimas três décadas. O mais marcante para as ciências sociais não foi o "colapso da modernização”, título do livro publicado em 1991 por Robert Kurz, mas o colapso da União Soviética, no mesmo ano. Já desde a publicação de Lyotard sobre a

Artigo recebido em novembro/2005 Aprovado em julbo/2006 "condição pós-moderna”, em 1979, surgiram inúmeras publicações que levantaram, de uma forma ou de outra, a hipótese de que a formação sóciohistórica contemporânea não seria mais compreensível se ela fosse entendida exclusivamente como sociedade moderna. Surgiu uma variedade de conceitos que tentaram transmitir a emergência de algo novo, algo tão radicalmente novo que legitimaria falar até de uma ruptura de época, como sugere a postulação da emergência de uma "pósmodernidade".

As ciências exatas, que nunca foram tão exatas assim, contribuíram, por sua vez, para perturbar os "pesquisadores sociais". Foram elas que convidaram a pensar o "caos determinístico" no âmbito socioeconômico (Prigogine, 1984) ou propuseram imaginar a história como um "campo de acontecimentos" dentro de um espaço com "n" dimensões (Eigen, 1989 e 1978). Assim estimulada, a teoria social lembrava-se nos últimos anos de algumas das suas mais valiosas e, freqüentemente 
esquecidas, tradições. Assim, Bauman chamou atenção em inúmeras publicações para a "ambivalência" da própria modernidade; Maffesoli constata, se não festeja, as "vagabundagens pós-modernas" e resgata questões existenciais para a sociologia, e assim adiante (Maffesoli, 2001 [1997]).

A "ruptura semântica" exigia novos conceitos para uma realidade transformada. Junto com a fala habermasiana, ainda cautelosa, da "nova intransparência", surgiram as primeiras propostas (Habermas, 1990 [1985]). Ulrich Beck alcançou um grande sucesso editorial quando lançou o livro A sociedade de risco (Beck, 1986). Desde então, assistimos a um debate sobre o "risco" e a "sociologia do risco" (Luhmann, 1991), que expressa o espírito de incerteza da época.

O livro de Beck não foi até agora, apesar do seu grande sucesso editorial na Alemanha e em outros países, traduzido para a língua portuguesa. Apesar da dificuldade de acesso, Ulrich Beck tornou-se também uma referência no Brasil, com a coletânea Modernização reflexiva, de 1994, que une contribuições de Anthony Giddens, Scott Lash e do próprio Ulrich Beck (Beck, Giddens e Lash, 1994). Muitos pesquisadores usam hoje o termo "sociedade de risco" de forma corriqueira e descobrem riscos nos mais variados contextos. Parece que o já mencionado clima de crise e incerteza que precedeu e acompanhou o fim do comunismo soviético e o paralelo desenvolvimento tecnológico em escala global encontrou um público, também, teoricamente cada vez mais inseguro e ávido para abraçar novos paradigmas. Descobrir "riscos", como Beck, ou perceber a situação histórica como "intransparente", como Habermas, são somente sintomas de um estado de espírito caracterizado pela consciência da contingência da modernidade e pela crescente "incredulidade nas metanarrativas", das quais Lyotard fala.

Assim, ganha maior plausibilidade a hipótese de que o curioso sucesso do conceito "sociedade de risco" deve-se mais a essas circunstâncias históricas e teóricas do que à força de convicção de uma teoria sociológica consistente sobre uma nova formação social. Não precisamos aqui discursar mais uma vez detalhadamente sobre a argumentação de Beck (cf. Brüseke, 2001). No contexto desta reflexão meramente conceitual sobre risco e contingência queremos brevemente lembrar as teses centrais de Beck, convidando em seguida para uma reflexão mais ampla.

\section{As teses centrais sobre a sociedade de risco: Ulrich Beck}

De maneira geral, pode-se levantar nove tópicos que traduzem as teorias centrais do autor:

- A sociedade industrial torna-se uma sociedade cada vez mais saturada, contudo repleta de imponderações e efeitos não-intencionados.

- Existem riscos individuais e riscos globais. Riscos individuais sempre existiram, mas distinguem-se de forma radical dos riscos que a modernidade traz consigo. O mundo encontrase hoje em uma disposição de perigo que se expressa de forma exemplar na ameaça nuclear. A disposição de perigo atinge potencialmente todo o mundo. O risco é global.

- A distribuição dos riscos é desigual.

- $\quad$ O risco que a civilização corre não possui evidência; surge aí a necessidade da reflexão científica sobre a modernização.

- A sociedade industrial entrou numa fase de modernização reflexiva, na qual se tornou tema para si mesma.

- Existe uma distinção entre a cientificização reflexiva e a cientificização simples. A primeira é a cientificização voltada a si mesma. O conceito da modernização reflexiva abrange tanto a modernização refletida, não por movimentos sociais críticos da sociedade industrial-capitalista, mas também da modernização da própria modernização.

- A invisibilidade imediata dos riscos da modernização coloca os cientistas e os políticos numa posição-chave, como intérpretes do perigo. Por meio deles um risco pode sofrer minimização ou dramatização; $O$ risco é aberto para processos sociais de sua definição.

- Os riscos relativizam as posições de classe. Ricos e pobres, empresários e assalariados sofrem ou podem sofrer, por exemplo, as conseqüências da poluição.

- Os riscos produzem também novas desigualdades internacionais. Elas são novas 
porque não correspondem necessariamente a dicotomias antigas entre metrópole e periferia.

\section{O que significa risco?}

A palavra risco aparece hoje em qualquer contexto discursivo que quer alertar para as conseqüências futuras negativas de uma variedade praticamente ilimitada de fenômenos e processos. Por isso, é mais do que oportuno lembrar de algumas conotações básicas do emprego da palavra risco na qualidade de um conceito. Dispomos hoje de vários trabalhos científicos que, nos anos que seguiram a publicação de Beck, se debruçaram sobre esta tarefa. Entre os trabalhos exaustivos sobre o "risco" na modernidade, como o de Wolfgang Bonss (1995), há estudos mais teóricos como o de Niklas Luhmann (1991). Coube a Luhmann o mérito de ter tentado uma primeira aproximação sistemática ao problema do "risco" no campo da sociologia, dedicando a ele o livro A sociologia do risco (Luhmann, 1991).

Este autor reclama que a sociologia ainda não conseguiu oferecer mais do que observações do óbvio a respeito desse assunto. "Sociedade de risco" é um conceito de moda, ele já afirmara, com uma ironia que lhe é peculiar. E mais uma vez como prova do seu bom humor, Luhmann diz:

Como as outras disciplinas também a sociologia parece partir do pressuposto que os danos são danosos, que desvantagens devem preferencialmente ser evitadas e que isto vale ainda mais para danos que podem assumir extensões catastróficas. [...] Todavia não alcançamos com isso um conceito teórico e a pesquisa fica no estado da fascinação pelo horrível (Luhmann, 1990, p. 140).

Luhmann propõe uma distinção entre risco e perigo. Assim, só devemos falar de riscos quando possíveis danos são conseqüências da própria decisão. Não obstante, seria mais adequado falar de perigos quando os danos ou as perdas estão relacionados com causas fora do próprio controle.

A modernidade na sua fase atual não conhece mais um télos histórico; o futuro pode realizar este ou aquele projeto. Na medida em que a trajetória histórica se abre e se torna uma função de decisões individuais, assumem estas a responsabi- lidade também para possíveis fracassos e perdas. O risco de uma decisão pressupõe a consciência desses danos possíveis, assim como o cálculo da decisão de viajar de avião, por exemplo, conta com a probabilidade de chegar sem acidente aéreo ao lugar do destino. Quando acontece um desastre, o que é improvável mas não impossível, o dano assumido torna-se algo real. Quem fuma, diz Luhmann, assume o risco de morrer de câncer, mas para os outros o câncer continua sendo um perigo (Idem, p. 148). Alguém que assume o risco de morrer atrás do volante do seu carro, o que seria uma possível conseqüência da decisão de andar em alta velocidade, representa um perigo para os pedestres e outros motoristas. Assim a mesma ação é um risco para um e um perigo para os outros. Percebemos como a operação de distinção de Luhmann entre risco e perigo não pode evitar o fato de que os dois estão interligados. Todavia, a argumentação do autor chama a atenção para algo essencial, que é a distinção entre um dano hipotético em conseqüência da própria ação consciente e um dano hipotético em conseqüência da ação dos outros, da natureza ou de outras causas fora do próprio controle.

\section{Contingência e teoria social: Luhmann}

Luhmann não se contenta com uma polêmica apenas sobre a "sociologia do risco"; já em 1992 ele chama atenção para a "contingência como valor próprio da sociedade moderna" (Luhmann, 1992). Com isso o autor abriu a sociologia dos anos de 1990 para um debate que, além de operar com um conceito antigo, cria uma nova sensibilidade teórica para imprevisibilidades e possibilidades surpreendentes no campo dos acontecimentos. Na verdade, não é somente Luhmann que se dedica à questão da "contingência"; Richard Rorty, já em 1989, discorria em contextos da ciência literária e da filosofia sobre "contingência e ironia", contribuindo para um ciclo de reflexões que até então não perderam nada do seu vigor inicial (Rorty, 1992 [1989]). Muito pelo contrário, podemos verificar um número crescente de pesquisadores tentando "explorar" o termo da contingência nas áreas mais diversas (Makropoulos, 1997 e 1999; Brüseke, 2002). 
O senso comum confunde facilmente o conceito de contingência com o "acaso" ou com "algo imprevisto". Essa compreensão deriva-se, também, do uso da expressão "contingências" para denominar, na fala cotidiana, os acontecimentos casuais que sempre atravessam as trajetórias planejadas. Nessa linha de raciocínio, o administrador elabora "planos de contingência" para desenhar alternativas de ação em caso do surgimento de eventualidades que põem em cheque a execução dos planos empresariais. Assim, o "plano B" é uma resposta aos efeitos não-esperados e a qualquer tipo de emergência de novidades relevantes (Chandler, 1962; Burns e Stalker, 1961; Lawrence e Lorsch, 1972).

Apesar do fato de a representação cotidiana das "contingências" e, também, do uso desta palavra nos "planos de contingência" tocar no problema da contingência, é necessário enfatizar que $o$ conceito de contingência não significa simplesmente "acaso", "imprevisto", "inesperado" ou algo desse gênero! É importante ter isso em mente para evitar um encaminhamento errôneo das reflexões logo na entrada. Se contingência significasse simplesmente acaso, seria melhor adotar logo esta palavra, em vez de introduzir um conceito novo.

O que, então, significa contingência? O conceito é usado na filosofia desde Aristóteles e na teologia por Tomás de Aquino (endechomenon, gr.; contingens, lat.) e, mais recentemente, na sociologia, nas obras de Talcott Parsons e do já citado Niklas Luhmann. A contingência denomina algo que não é necessário, nem impossível e, dessa forma, diz respeito à abertura fundamental da experiência humana no âmbito social. O conceito de contingência também se estende à percepção do mundo que depende de distinções (entre aquilo que está dentro do sistema e aquilo que está no seu ambiente); essas distinções podem ser feitas desta ou daquela maneira, são então "contingentes". A necessidade da redução de complexidade deriva-se dessa abertura fundamental do agir e perceber humano. Sistemas sociais têm a função de reduzir a complexidade e controlar a contingência, possibilitando assim um agir direcionado e com sentido por parte do ator social.

"Tudo é contingente que nem é necessário, nem impossível" (Luhmann, 1992, p. 96). Nesta definição o conceito de contingência é resultado de uma dupla negação, primeiro da necessidade e, segundo, da impossibilidade. Uma lógica bipolar, baseada no "ser" ou "não-ser", traz seus problemas. Precisamos aparentemente de um terceiro pólo, o da indefinição, para captar melhor a mensagem deste curioso conceito. Luhmann pergunta por isso com perspicácia: "Existe de todo uma teoria que pode manusear o conceito de contingência?" (Idem, p. 98).

Para responder a esta pergunta, ele introduz os conceitos de observação de primeira e de segunda ordem. Observações simples, chamadas de primeira ordem, usam diferenciações, mas ainda não geram, para o observador, a contingência. Somente as de segunda ordem, que são observações de observações, podem ver a contingência. Estas reduzem o campo da observação: exclusivamente o observar está sendo observado. Tal procedimento significa, de um lado, uma redução de complexidade, mas abre, de outro, a possibilidade de um aumento de complexidade no campo da observação da observação. Eu posso perguntar por que um observador observa exatamente esta e não uma outra coisa. Assim, a observação observada torna-se contingente, pois ela é o que é, mas poderia ser uma outra. Através da observação do observador abre-se a possibilidade de aplicar também a consciência da contingência com intenção terapêutica ou sociológica. Quando um observador não vê algo que é evidente, isto fica para ele na latência. A sua observação atribui a ele, ao observador de primeira ordem, a incapacidade de ver o que ele não pode ver.

Quando dois indivíduos entram em comunicação surge o problema da contingência dupla. Isso resulta da dependência de cada indivíduo da ação (ou informação) contingente do outro. "Eu sei que você sabe e você sabe que eu sei." Esta situação faz na interpretação de Luhmann da comunicação correta uma mera possibilidade ou até uma improbabilidade (Luhmann, 1992) facilmente verificável no momento do pênalti, quando jogador e goleiro tentam fazer seus cálculos de ação na base da dupla contingência. Em decorrência do aumento da complexidade das sociedades modernas, resultado da sua diferenciação funcional, crescem as opções de ação para cada indivíduo. Isso, por sua vez, resulta no aumento de experiências da contingência por parte do ator social. 


\section{Risco e contingência}

Um olhar mais geral sobre o uso do conceito de risco na literatura leva a conclusão de que existem basicamente duas concepções de risco. A primeira, que podemos chamar de conceito "restrito de risco", segue a definição de Luhmann, isto é, quando um ator sabe das conseqüências do seu agir e procede na consciência tanto do possível sucesso da sua ação como de possíveis danos. A segunda, que podemos chamar de conceito "amplo de risco", vai mais além e inclui aquilo que Luhmann denomina perigo. Assim há uma "zona de risco" quando se trata, por exemplo, de regiões onde terremotos são, por causa da localização geográfica, freqüentes; ou quando se trata de risco de uma guerra nuclear; risco de uma epidemia ou risco da desertificação em regiões com um uso excessivo do solo. Esse conceito amplo quer alertar para a emergência de futuros eventos danosos para o homem, sejam eles frutos de uma ação individual, sejam resultado nãointencionado de uma ação coletiva, sejam ainda simplesmente fenômenos naturais com efeitos negativos para a sociedade.

Em termos operacionais, o conceito restrito, favorecido por Luhmann, é sem dúvida mais preciso. Não obstante, a aplicação do conceito amplo de risco ganhou, por causa do seu largo uso, uma importância que não podemos simplesmente eliminar no âmbito do combate conceitual. Avaliamos que a grande aceitação do conceito amplo de risco é resultado, exatamente, da crescente consciência da contingência, que se expressa sui generis, isto é, a consciência de contingência não se apresenta sob a denominação ("filosoficamente correta") de contingência, mas sob outras formas lingüísticas. Nesse sentido, o discurso do risco é uma maneira de se comunicar num campo de eventos contingentes. Tal categoria é sempre, para o homem, uma ameaça hipotética. Existem outros eventos avaliados como chance, sorte, benção, graça etc., que, apesar de ter a mesma estrutura contingente do risco, ocultam facilmente seu caráter, uma vez que são vividos de forma positiva. O homem tem a compreensível inclinação de atribuir as "contingências positivas" ao seu próprio mérito e buscar a culpa para as "contingências negativas" fora da própria responsabilidade.
Entendendo o "risco" desta maneira, ou seja, como uma expressão moderna da consciência da contingência, é preciso voltar no tempo para elucidar a consciência pré-moderna da contingência. Essa viagem vai nos trazer, em determinado momento, de volta ao presente.

\section{O Deus necessário e o contingens: Tomás de Aquino}

O conceito de contingência existe desde Aristóteles (endechomenon). Não obstante, a consciência da contingência aumenta dramaticamente com a adoção da "dúvida metódica" pela filosofia ocidental. Descartes (1951 [1637]) introduz e valoriza positivamente observações de segunda ordem, passo decisivo e marcante para os tempos modernos. Observações de segunda ordem são a especialidade dos críticos de qualquer gênero. Afinal, a crítica é somente possível quando feita neste segundo nível das observações. Como uma faceta do processo reflexivo como um todo, a crítica passou a ser a paixão dos pensadores modernos. $\mathrm{O}$ intelectual, que nasce na Idade Média com a fundação das primeiras universidades, é o portador privilegiado da consciência da contingência, resultado também do aumento da reflexividade da teologia cristã. Ademais, o intelectual não consegue se levantar a uma auto-reflexão, a uma observação de terceira ordem, que revelaria a sua própria consciência crítica como contingente.

Parece logicamente impossível pensar o infinito nas circunferências do finito. Todavia, seria possível, partindo de observações do finito, deduzir racionalmente a sua "existência". Dessa maneira Tomás de Aquino apresenta na Suma Teológica (1273) cinco vias que provam "existência" de Deus: 1) do movimento deduz-se a força última, imóvel; 2) das causas, chega-se a uma primeira causa, não-causada; 3) o possível existe, somente porque algo o faz existir; 4) dos variados graus de perfeição deduz-se a existência da perfeição e da verdade absoluta; 5) a regularidade nos fenômenos naturais é intencional; Deus é a inteligência primeira e ordenadora na raiz da finalidade das coisas. Desenvolvidas com base nas quatro "causas aristotélicas" (causa materialis, causa for- 
malis, causa finalis e causa efficiens), essas vias são, no fundo, as argumentações que destacam a necessidade de Deus, apontando o não-necessário que pode ou não ser. As cinco "provas da existência de Deus" de Aquino podem ser vistas como somente cinco perspectivas de observação do mesmo fenômeno, as quais revelam diferentes modos de manifestação do contingente (Thomas de Aquino afirma: Contingens est, quod potest esse et non esse, Sum. Th. I, 86, 3 c). Na sua compreensão, o contingente pressupõe o absoluto. Em outras palavras, a existência do condicionado exige a existência do incondicionado, isto é, Deus. Seria impossível a existência apenas de seres contingentes. O contingente pode ser causa de outro contingente, e assim por diante, mas a última ratio do ser contingente é o Ser que é por conta própria, é o ens a se, Sein aus sich, ou "Ser de si mesmo", Deus.

Tomás de Aquino separa a necessidade absoluta do ser acidental. Assim, seu conceito de contingência aponta o que é acidental, o que pode ser de um jeito ou de outro, mas não abrange e inclui a necessidade. Esse entendimento ainda encontramos hoje, quando ouvimos referências às "contingências da vida cotidiana", ou quando se emprega o termo contingência como se fosse sinônimo de acaso. Os entes contingentes, todavia, participam no Ser absoluto. Tomás ainda "esquece", como diria Heidegger, a "questão do Ser" e dissolve a possível ambiguidade da contingência dos Seres na dicotomia entre o finito e o infinito, o condicionado e o não-condicionado, o perfeito e o imperfeito. Não obstante, a estrutura paradoxal da contingência aparece, já em Tomas de Aquino, na curiosa problemática da trindade,. Sendo "Um em três", o Deus absoluto torna-se "carne" e participa, iluminado pelo espírito santo, das amarguras da vida, humana e finita. Pensando radicalmente a idéia do Deus cristão, podemos até descobrir que este, somente quando "desce" ao nível do singular, quando se esgota num projeto singular e finito, mostra que é absoluto até na sua dedicação radical ao relativo. O absoluto não seria absoluto se este não tivesse a possibilidade de se manifestar, quando quiser, no relativo. Transformando dessa maneira (e com o devido respeito) a teoria de Tomás de Aquino, reinserimos a necessidade (o fundamento) naquilo que é.
O conceito de contingência, que nós favorecemos, lembra a estrutura paradoxal presente na doutrina da trindade. Seu emprego hoje somente faz sentido quando carrega no seu significado acidental aquilo que é necessário. Somente da simultânea presença de estruturas necessárias e eventos e qualidades acidentais o conceito ganha força e sua razão de ser. A definição da contingência empregada por nós, portanto, seria: "Algo é necessariamente como é, mas também poderia ser diferente".

$O$ atual conceito de necessidade acompanhou a revolução paradigmática do século XX. Primeiro, constatou-se que as leis científicas da mecânica de Newton valem para espaços, tempos e grandezas "médias", mas são relativizadas quando se trata do extremamente grande (o universo) e o extremamente pequeno (a subestrutura do átomo). Também passamos pela revolução termodinâmica que (no mínimo) introduziu de forma convincente o conceito da "irreversibilidade", já nos anos de 1860, o que contrasta com a reversibilidade e a congruência temporal da física clássica. O que, todavia, transformou nossa percepção de estruturas e processos necessitários são alguns paradigmas desenvolvidos por Einstein, Max Planck e Heisenberg. A relatividade, a física quântica e as relações de incerteza tornaram muitos fenômenos físicos antinômicos e paradoxais. Com isso, apresenta-se o Ser numa perspectiva radicalmente diferente. Uma perspectiva não somente nova para a física, mas, também, para a filosofia, que encontrou em Heidegger o pensador do "segredo do Ser".

Em suma, o conceito de necessidade que propomos integrar no conceito contemporâneo de contingência não é mais uma grandeza "metafísica" de outrora. Quem, todavia, quer vincular a idéia de "necessidade" com a idéia de Deus deveria ir além de Tomás de Aquino e resgatar as fontes da teologia (mística) de pensadores como Mestre Eckart, Bernardo de Claraval e João da Cruz, entre muitos outros. Aqui se apresenta, já no contexto "teo-lógico", o absoluto como um paradoxo. Quem busca a gestão de riscos deveria, então, saber que esse projeto não pode escapar das antinomias e das instabilidades contidas no próprio Ser, que é necessariamente como é, mas, também, poderia ser diferente, exatamente no momento em que nós menos esperamos. 


\section{Crítica do conceito de contingência de Rorty}

Rorty, como muitos outros contemporâneos, apropria-se do conceito de contingência, transpondo-o para um plano antimetafísico, reduzindo, assim, seu teor. O que queremos dizer com isso? O contingens não é entendível, em Tomás de Aquino e em toda teologia e filosofia até Nietzsche, se o separamos do seu oposto, do totalmente incondicionado, que é Deus. Deus é a necessidade absoluta, sem nenhuma razão de ser, fora de si ("Eu sou quem eu sou!"). O contingens é o dependente, o criado e o acidental, que pode ser ou não. A última causa, pela qual algo pode ser ou não, ou porque algo é de tal maneira e não diferente, está fora do alcançe da razão humana ("Os caminhos do Senhor são insondávéis.") O contingens é "acidental", mas assegurado pela vontade de Deus, que lhe dá sentido, mesmo que este seja incompreensível. Grandes infortúnios que castigam o homem aparecem, assim, sob uma nova luz: a doença incurável ou a perda súbita da vida num "acidente" podem ser suportadas como "provação", ser aceitadas como "castigo" e "penitência " ou fazem transparecer de forma enigmática, na mística da dor, o divino (Brüseke e Sell, 2006).

O contingens, sem o seu oposto, não faz sentido, é um conceito pela metade, amputado do seu sentido mais profundo. Todavia, tentamos pensar, em tempos modernos, sem recorrer a categorias metafísicas. Tal empreendimento leva, em muitos casos, a uma transposição de categorias metafísicas para um plano laicizado, já apontado por Carl Schmitt no âmbito da ciência política, e conduz freqüentemente a um emprego de categorias "tradicionais" sem informar sua origem. Silenciando a genealogia metafísica dos conceitos, e de muitos dos nossos valores, essa transposição aproveita, não obstante, seu poder de convicção.

O contingens, sem sua dimensão necessária, só pode informar sobre eventos desprovidos de sentido. A contingência separada do seu fundamento aparece como o radicalmente gratuito na literatura e na filosofia do século XX. Desde Franz Kafka até Albert Camus e o jovem Jean-Paul Sartre, entre outros pensadores, segue a corrente daqueles que sabiam que mesmo a própria vida é, mas poderia não ser. O contingens sem o seu sentido oculto transforma-se (com certa necessidade) no "absurdo"; o evento possível e surpreendente no "acaso"; a possível emergência de uma perda, no "risco".

O uso do termo "contingência" quando, na verdade, se deseja falar do "acaso" não faz o menor sentido, apenas empobrece esse conceito. Sua riqueza deriva-se exatamente da relação simultânea, tensa e, por vezes, enigmática com a necessidade e a possibilidade. É difícil manter hoje a argumentação de Tomás de Aquino fora de contextos teológicos; não obstante, podemos conservar a estrutura básica do seu entendimento da contingência, sem exigir de nós mesmos um sacrificium intelectum.

Se queremos fazer uma referência ao necessário e ao possível a um só tempo, apenas uma idéia de "contingência" será concernente: algo é necessariamente como é, mas, também, poderia ser diferente. Sem a insistência na necessidade seria inexplicável o sucesso da ciência e da técnica modernas. As ciências (exatas) referem-se a regularidades contidas no próprio Ser, apresentam-nas na forma de leis científicas e abrem o caminho à sua manipulação técnica.

\section{A exploração da contingência}

A sociedade industrial explora a contingência. Explora na base dos conhecimentos científicos daquilo que é possível. A grande metáfora da contingência é "o plástico", que demonstra a plasticidade daquilo que é. Ser "plástico" significa ser cientificamente transparente e acessível às manipulações técnicas. O "plástico" é a realização de uma possibilidade; é uma possibilidade que emerge de estruturas determinadas por padrões que seguem suficientemente regras causais. A contingência é, então, muito mais do que o acaso, a aleatoriedade ou o risco que o indivíduo corre quando se encontra com um perigo inesperado. A contingência "abraça" esses conceitos e faz deles somente um aspecto de uma realidade "plástica", determinada e livre, no mesmo (!) momento.

É conhecido que, em comparação com outros mamíferos, o homem é pobre de instintos. Essa deficiência obriga a criança humana a adqui- 
rir estratégias de sobrevivência (táticas de vida, diria Oswald Spengler) culturalmente, imitando os adultos (Spengler, 1993 [1931]). A fraca determinação do comportamento humano pelos instintos significa também, usando um linguajar mais filosófico, que o homem "nasce livre". Essa "liberdade" é desde cedo um desafio, pois cada indivíduo confronta-se com a possibilidade do fracasso dos seus esforços de assimilar as estratégias de sobrevivência com sucesso. Também não parece tão evidente que as práticas tradicionais são as mais indicadas em qualquer situação. Infância e juventude são, em maior ou menor intensidade, o palco da contestação das regras herdadas. O mundo em permanente mudança não permite a fixação da ação daquele que quer sobreviver, também, em contextos transformados. A resposta à mudança externa é a inovação da tática de vida, e os exemplares juvenis das espécies tendem a "brincar" com as possibilidades abertas. "Brincando com o fogo" descobriu o homem sua utilidade, e garantiu sua sobrevivência em áreas atingidas por choques climáticos. A fraca determinação instintiva do ser humano fez da "raça humana" a ponta de uma variação evolutiva da vida orgânica capaz de penetrar os mais diversos espaços. O homem é o Ser que possui entre os Seres a mais íntima ligação com a possibilidade de poder ser diferente, de poder viver diferente. A diferenciação das suas táticas e estilos de vida nasce da sua incapacidade de se entregar plenamente a uma determinação biológica, característica para todas as outras espécies. O homem fez da contingência sua vida, ou deveríamos dizer o contrário? A vida fez do homem o guardião engenhoso da contingência.

\section{O Ser é contingente}

O conceito de contingência é ambíguo; importante lembrar, mais uma vez, que concerne a um só tempo à necessidade e à possibilidade. $\mathrm{Na}$ passagem para os tempos modernos, podemos observar a exploração cada vez mais sistemática do lado necessitário do Ser. O que entendemos hoje como ciência é um conjunto de conhecimentos sobre regularidades tanto morfológicas como processuais. Essas regularidades fascinaram os primeiros cientistas, cujos novos conhecimentos abriram caminho para as primeiras experiências científicas, pois o Ser, na medida em que segue suficientemente regras causais, é conhecível e manipulável. Os grandes sucessos da tecnociência na Revolução Industrial encontram aí sua base.

Não obstante, nunca deixou o Ser sua qualidade de ser plenamente contingente - e não somente necessitário -, lembrando, quando o homem menos espera, do seu caráter aberto. Essa "abertura" do Ser não desmente as chamadas leis da natureza, as quais, todavia, sofrem uma reinterpretação que limita a sua validez a determinados distritos de realidade (Heisenberg, 1989 [1939]). Da perspectiva atual, podemos observar, nas primeiras décadas do século XX, uma convergência do pensamento vanguardista tanto do campo da física como da filosofia; convergência que também se expressa em inúmeras produções literárias e artísticas e se refere a um novo entendimento do Ser (e de ser). Einstein, Planck e Heisenberg expressam essa ruptura semântica com os meios da física, ao passo que Heidegger e Sartre empregam os instrumentos discursivos da filosofia para afirmar que o Ser não tem fundamento. "Sein bleibt als Sein grund-los" (Heidegger, 1992 [1957], p. 185).

Heidegger apresenta o homem, em Ser $e$ Tempo, como lançado para dentro do mundo. Sendo, o homem está "aú", "no mundo", "com os outros", "fatual", "histórico" e "preocupado", porque está condenado a existir sabendo da sua temporalidade (o que inclui a consciência da possibilidade da própria morte em qualquer instante) e das suas condições existenciais, circunstanciais e limitadas (Heidegger, 1993 [1927]). O Ser-aí é sem poder ter escolhido estar aí. Não há condenação mais dramática do que essa à própria existência temática bastante explorada na obra literária de Sartre. Heidegger, muito antes de Sartre, apresenta a existência do self como "possibilidade necessitária", dizendo: "Dasein ist je seine Möglichkeit [...]" (SuZ, 42) ["O Ser-ai é sempre a sua possibilidade"]; "Und weil Dasein wesenhaft je seine Möglichkeit ist, kann dieses Seiende in seinem Sein sich selbst wäblen, gewinnen, es kann sich verlieren, bzw. nie und nur scheinbar gewinnen [...] (SuZ, 42) ["E por que o ser-aí é sempre essencialmente sua possibilidade é que ele pode, em seu ser, isto é, sendo, 
'escolher-se', ganhar-se ou perder-se ou ainda nunca se ganhar ou somente se ganhar 'aparentemente" (Idem, p. 78)]. Critério para a escolha do ganho ou da perda é a categoria da autenticidade, que funciona como um redutor de complexidade, ou um meio da Möglichkeitsbändigung (domesticação das possibilidades) no mar das livres escolhas entre perdas e ganhos (Makropoulos, 1990). No entanto, o que nos interessa mais neste momento é que a ontologia fundamental de Heidegger, e, a partir de então, de toda a filosofia e a literatura existencialista, apresenta o Self como um ser que é a sua própria possibilidade. Isso não quer dizer o mesmo que ter uma possibilidade. Quando tenho uma possibilidade, fica ela, assim dizer, fora de mim, e eu posso realizá-la ou não. No entanto, quando sou a minha possibilidade, ganha ela um fundamento necessário, que, todavia, está aberto, porque é permeado por possibilidades a serem escolhidas, ou não. Sartre cunhou essa compreensão da existência humana na conhecida fórmula: "O homem é condenado a ser livre". Usando uma contradição em si, pois a liberdade não pode se derivar de uma condenação, fala Sartre daquilo que é caro, também, para Heidegger, isto é, a descrição do homem como um ser contingente.

\section{Padrões de possibilidade}

A afirmação "tudo é possível" tem mais a função de despertar a nossa mente para a variedade de trajetórias e estados possíveis do que expressar adequadamente o campo dos acontecimentos. Na verdade, não é "tudo" que é possível, mas é possível muito mais do que a mente comum acha que seja. A possibilidade, também, não cai do céu como um meteorito cai no nosso jardim, apesar de surpreender o sujeito que foi atingido por ele. A surpresa cria freqüentemente a impressão da completa falta de regras, que, todavia, não deixam de existir para determinados distritos da realidade. Devemos lembrar que a existência de regularidades do comportamento das coisas faz com que elas sejam passíveis de manipulações técnicas e insights científicos.

Nem tudo é possível, mas muito mais do que nós comumente imaginamos. Sabemos muito pouco sobre o possível. Este conhecimento inci- piente leva-nos, às vezes, a esperar demais, às vezes a esperar de menos ou, em outros momentos, a esperar coisas impróprias. Esperamos, por exemplo, do campo político a realização de possibilidades e expressamos essa esperança em utopias políticas. Mas a contingência do campo histórico não é $u$ topos, nenhum lugar. O lugar da historia humana é limitado temporal e fisicamente; é limitado em qualquer uma das suas dimensões culturais, econômicas e sociais, embora continue sendo um campo aberto. Estudos sobre as nossas possibilidades (reais) distinguem-se nitidamente de utopias políticas, porque elas trabalham com probabilidades ou padrões de possibilidades e não partem do desejo, que é um potente gerador de fantasias prazerosas. Fantasias são uma expressão dos padrões de possibilidades da nossa mente; no entanto não constam no arsenal das possibilidades da realidade social.

Em outras áreas podemos observar, nos últimos tempos, grandes avanços referentes à percepção de padrões de possibilidades, relevantes para a sociedade. Assim, depois de uma fase meramente reativa, quando se tratava de catástrofes, surgem a cada ano mais estudos sobre suas causas, para chegar a um mínimo de planejamento e ação preventiva. Nesse contexto, ganhou o conceito ampliado de risco bastante relevância, pois permite trabalhar com cenários catastróficos dentro dos padrões de possibilidades de cada caso. Estudos sobre riscos concernem a um determinado campo de eventos onde estão em jogo perdas indesejadas. A contingência do Ser permite que possamos cercar tais riscos com meios probabilísticos, permite que possamos trilhar caminhos menos arriscados. Possibilidade, no entanto, não deve ser confundida com probabilidade, assim como probabilidade não é sinônimo de contingência.

O pensamento probabilístico é útil para descrever o comportamento de grandes conjuntos. A taxa de mortalidade por faixa etária, por exemplo, informa a seguradora sobre o "tempo de vida residual" (Restlebenszeit) do segurado. Para o sujeito em si, esses dados dizem relativamente pouco, pois "a morte está à espreita debaixo de tudo" (Malcolm Lowry, 1981 [1947], p. 266); do ponto de vista do indivíduo, a "expectativa de vida" de morrer tem uma probabilidade de 100\%; e até a consumação deste fato inevitável o sujeito vive 
com a consciência do risco de uma morte súbita a qualquer momento. Para ele, a probabilidade não expressa a realidade individualmente vivida. Não obstante, ela alimenta a consciência do risco (ou da chance) com informações (ou expectativas) dentro dos padrões de possibilidades de um organismo vivo. O possível é o companheiro fiel do necessário, lembrando o indivíduo da sua presença quando achar oportuno.

\section{Para finalizar...}

Falar da contingência não pode significar que o mundo está à disposição plena do homem. Muito pelo contrário, a contingência remete exatamente àquilo que Heidegger denominou o "segredo do Ser". As manifestações variadas do Ser fazem esquecer que o Ser desses Seres escapa de um acesso científico e técnico pleno. A perspectiva da ciência e da técnica é sempre científica e técnica; nós não podemos observar o que não podemos observar, diria Luhmann. Heidegger introduz o conceito do desocultamento técnico para caracterizar o acesso específico e reduzido da técnica moderna àquilo que é (Brüseke, 2000 e 2001).

A contingência parece ser um conceito impossível, uma vez que viola a lei da lógica aristotélica que expulsa a contradição e exige identidade. Algo é ou não é; nunca pode ser e não ser ao mesmo tempo. Por isso, a lógica formal apresenta, em relação à contingência, seus problemas. Quem quer compreender o que a constatação da contingência do Ser significa vai, em certo momento, tomar uma atitude mais contemplativa, com a qual o pensar se abre para aquilo que está aberto. A viagem na direção do aberto do Ser deixa, a partir de um dado momento, a linguagem científica para trás...

Nossa referência a Tomas de Aquino e sua leitura "às avessas" podem ajudar a recuperar o sentido do contingente, ou seja, é contingente devido a seu condicionamento pelo incondicionado. Integrando o incondicionado no condicionado, como sugere Heidegger a respeito do aberto do Ser, descobrimos, além do horizonte plástico da consciência moderna, algo que tínhamos esquecido - a bifurcação entre o plástico e o aberto do Ser é o lugar onde nos encontramos; tomar o caminho certo é uma chance, perdê-lo é, por assim dizer, um risco.

\section{BIBLIOGRAFIA}

ALTHUSSER, Louis. (1978), "Enfin la crise du marxisme", in Il Manifesto (org.), Pouvoir et opposition dans les sociétes postrevolutionaires, Paris, Le Seuil, pp. 242-253.

AQUINO, Tomás de. (1996), Tomás de Aquino. Bauru, Nova Cultural (col. Os Pensadores).

BAUMAN, Zigmunt. (1999), Modernidade e ambivalência. Rio de Janeiro, Zahar.

BECK, Ulrich. (1986), Risikogesellschaft. Frankfurt, Suhrkamp.

BECK, Ulrich; GIDDENS, Anthony \& LASH, Scott. (1994), Reflexive modernization: politics, tradition and aesthetics in the modern social order. Stanford, Stanford University Press.

BLOOM, Harold. (1973), Anxiety of influence. Nova York, Oxford University Press.

BRÜSEKE, Franz Josef. (2001), A técnica e os ris$\cos$ da modernidade. Florianópolis, EDUFSC.

(2002), "A descoberta da contingência pela teoria social". Sociedade e Estado, 17 (2): 283-308, jul./dez.

BRÜSEKE, Franz Josef \& SELL, Carlos. (2006), Mística e sociedade. São Paulo, Paulinas.

BONSS, Wolfgang. (1995), Vom Risiko. Unsicherheit und Ungewissheit in der Moderne. Hamburg, Hamburger Edition.

BURNS, T. \& STALKER, G. M. (1961), The management of innovation. Londres, Tavistok.

CHANDLER JR., A. D. (1962), Strategy and structure: chapters in the history of American industrial enterprise. Cambridge, Massachusetts, MIT Press.

DAVIDSON, Donald. (1986), Wabrheit und Interpretation. Frankfurt am Main, Surkamp. 
DERRIDA, Jacques. (1972), Schrift und Differenz. Frankfurt, Suhrkamp.

DESCARTES, René. (1951 [1637]), Discurso do método. Rio de Janeiro, Tecnoprint.

EIGEN, Manfred. (1978), "The hypercycle: a principle of self-organisation". Naturwissenschaften, 65: 7-41.

(1989), "Evolution und Zeitlichkeit", in Aschoff et al.; Die Zeit: Dauer und Augenblick. München/Zürich, pp. 35-57.

FUKUYAMA, Francis. (1992), The end of history and the last man. Londres, Penguin.

GIDDENS, Anthony. (1991), As conseqüências da modernidade. São Paulo, Editora da Unesp.

GORZ, André. (1980), Adieux au prolétariat: au delà du socialismo. Paris, Editions Galilée.

HABERMAS, Jürgen. (1990 [1985]), O discurso filosófico da modernidade. Lisboa, Dom Quixote.

. (2001/2002), Die Zukunft der menschlichen Natur. Auf dem Weg zu einer liberalen Eugenik? Frankfurt, Suhrkamp.

HEIDEGGER, Martin. (1961), Nietzsche. Stuttgart, Neske, 2 vols.

(1992 [1957]), Der Satz vom Grund. Stuttgart, Neske.

(1993 [1927]), Sein und Zeit. Max Niemeyer Verlag, Tübingen (citado como SuZ).

HEISENBERG, Werner. (1989 [1939]), Ordnung der Wirklichkeit. München, Piper.

HOFFMANN, Arnd. (2005), Zufall und Kontingenz in der Geschichtstheorie. Mit zwei Studien zu Theorie und Praxis der Sozialgeschichte. Studien zur europäischen Rechtsgeschichte. Frankfurt am Main, V. Klostermann.

KLEPPER, Beate. (2003), Gnade und Erziebung Historisch-systematische Untersuchungen zu einer pädagogischen Kontingenzbewältigungsstrategie. Erziehung, Schule, Gesellschaft Band 29.
KOSELLECK, Reinhart. (1979), Vergangene Zukunft. Frankfurt, Suhrkamp.

KURZ, Robert. (1991), Der Kollaps der Modernisierung. Frankfurt, Eichborn Verlag.

LAWRENCE, Paul R. \& LORSCH, Jay W. (1972), O desenvolvimento de organizações: diagnóstico e ação. São Paulo, Edgard Blücher.

LOWRY, Malcolm. (1981 [1947]), Unter dem Vulkan. Hamburg, Rowohlt (1. ed. ingl. Under the volcano, Reynal and Hitchcock).

LISK, M. Th. (2000), "Fülleprinzip oder echter Indeterminismus? Zu Thomas' Begriff der Kontingenz". Disputatio Philosophica, 1: 105-124.

LUHMANN, Niklas. (1990), Ökologische Kommunikation. Opladen, Westdeutscher Verlag.

(1991), Soziologie des Risikos. Berlim/Nova York, Walter de Gruyter.

(1992), A improbabilidade da comunicação. Lisboa, Vega Passagens.

(1997 [1992]), Observaciones de la modernidad: racionalidad y contingencia en la sociedad moderna. Barcelona, Paidós.

LYOTARD, Françoise. (1986 [1979]), A condição pós-moderna. Rio de Janeiro, José Olímpio.

MAFFESOLI, Michel. (2001 [1997]), Sobre o nomadismo: vagabundagens pós-modernas. Rio de Janeiro, Record.

MAKROPOULOS, Michael. (1985), "Kontingenz und Selbstungewißheit. Bemerkungen zu zwei Charakteristika moderner Gesellschaften", in Gesa Dane et al. (eds.), Anschlüsse Versuche nach Michel Foucault, Tübingen, Edition Diskord, pp. 17-26.

(1990). "Möglichkeitsbändigungen. Disziplin und Versicherung als Konzepte zur sozialen Steuerung von Kontingenz". Soziale Welt, 41: 407-423. 
(1997), Modernität und Kontingenz.

München, Fink.

. (1998), "Modernität als Kontingenzkultur. Konturen eines Konzepts", in Gerhart von Graevenitz e Odo Marquard (eds.), München, Fink, p. 55-79, Kontingenz (Poetik und Hermeneutik, 17).

(2000), "Historische Kontingenz und soziale Optimierung", in Rüdiger Bubner e Walter Mesch (orgs.), Die Weltgeschichtedas Weltgericht? Stuttgart, Klett-Cotta, pp. 77-92 (Akten des Internationalen HegelKongresses).

PERLER, Dominik. (1988), "Notwendigkeit und Kontingenz. Das Problem der 'futura contingentia' bei Wilhelm von Ockham", in Von O. Pluta (org.), Die Philosophie im 14. und 15. Jahrbundert. In memoriam Konstanty Michalski (1879-1947), Amsterdam, Grüner, pp. 39-65.

PRIGOGINE, Ilya. (1984), A nova aliança. Brasília, Editora da UnB.

RORTY, Richard. (1992 [1989]), Contingência, ironia e solidariedade. Lisboa, Editorial Presença.

SLOTERDIJK, Peter. (1983), Kritik der zynischen Vernunft. Frankfurt, Suhrkamp, 2 vols.

(2000 [1999]), Regras para o parque bumano. São Paulo, Estação Liberdade.

SÖDER, J. (1999), "Kontingenz und Wissen: Die Lehre von den futura contingentia bei Johannes Duns Scotus". Theologie und Philosophie, 74: 426-429.

SPENGLER, Oswald. (1993 [1931]), O homem e a técnica. Lisboa, Guimarães Editores.

WETZ, Franz Josef. (1998), "Kontingenz der Welt Ein Anachronismus?", in O. Marquard e G. V. Graevenitz (orgs.), Poetik und Hermeneutik XVII, Kontingenz, München/Paderborn, pp. 81-106. 


\section{RISCO E CONTINGÊNCIA}

Franz Josef Brüseke

Palavras Chave: Risco; Contingência; Modernidade; Técnica; Pós-modernidade.

Referências à sociedade do risco já se tornaram corriqueiras e freqüentemente expressam mais o espírito de incerteza e insegurança da época do que uma teoria sociológica propriamente dita. Lembramos brevemente da contribuição de Beck e Luhmann, entre outros, para a sociologia do risco e partimos para uma interpretação do risco como aspecto da contingência da sociedade moderna. A consciência da contingência, apesar de estar presente no pensamento ocidental desde Aristóteles, ganha um impulso acelerador com a dúvida metódica de Descartes, para se impor dramaticamente com a implosão dos grandes sistemas metafísicos. Com referências a Tomás de Aquino e Richard Rorty, propomos reintegrar no seu sentido acidental aquilo que é necessário. Além de resgatar, dessa maneira, a estrutura paradoxal da contingência, podemos chegar a uma melhor compreensão dos padrões de possibilidade da modernidade técnica.

\section{RISK AND CONTINGENCY}

Franz Josef Brüseke

Keywords: Risk; Contingency; Modernity; Technique; Post-modernity.

References to the society of risk have become common and frequently tend to express more the spirit of uncertainty and insecurity of times than some properly defined sociological theory. The article briefly recalls the contribution of Beck and Luhmann, among others, to the sociology of risk and then moves towards the interpretation of risk as some aspect of the contingency of the modern society. Contingency awareness, though present in the occidental thinking since Aristotle, gained some accelerating impulse with Descartes' methodical doubting, before dramatically imposing itself with the implosion of the grand metaphysical systems. Making references to Tomas de Aquino and Richard Rorty, the article proposes reintegrating its essence to its accidental meaning. In rescuing the paradoxical structure of contingency it can then come to a better understanding of the standards of possibility for technical modernity.

\section{RISQUE ET CONTINGENCE}

Franz Josef Brüseke

Mots-clés: Risque; Contingence; Modernité; Technique; Post-modernité.

Les références à la société du risque sont devenues courantes et expriment fréquemment plutôt l'esprit d'incertitude et d'insécurité d'une époque qu'une théorie sociologique à proprement parler. Rappelons brièvement la contribution de Beck et Luhmann, parmi d'autres, pour la sociologie du risque et partons vers une interprétation du risque comme un aspect de la contingence de la société moderne. La conscience de la contingence gagne - malgré le fait d'être, depuis Aristote, toujours présente dans la pensée occidentale une nouvelle impulsion avec le doute méthodologique de Descartes, et s'impose dramatiquement avec l'implosion des grands systèmes métaphysiques. Avec des références à saint Thomas d'Aquin et Richard Rorty, nous proposons de réintégrer dans son sens accidentel ce qui est nécessaire. Ainsi, non seulement nous récupérons la structure paradoxale de la contingence, mais nous pouvons atteindre une meilleure compréhension des paradigmes de possibilité de la modernité technique. 